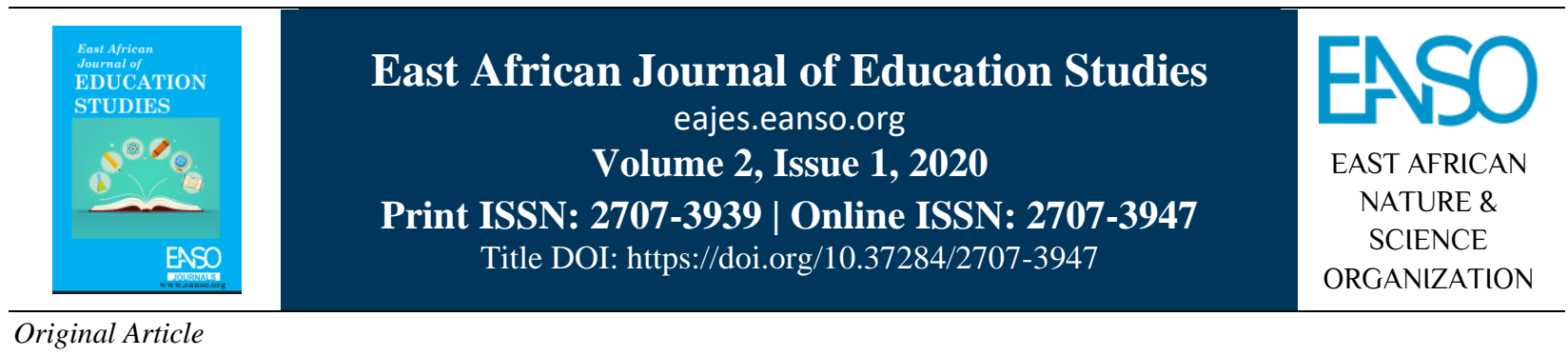

\title{
Performance Management and Quality of Lecturers' Services at Makerere University
}

\author{
Mary Anyango $^{1^{*}}$, Regis Zombeire Kamaduuka ${ }^{2}$ \& Dr. Maria Goretti Kaahwa ${ }^{3}$ \\ ${ }^{1}$ Department of Education Planning and Management, Kyambogo University, P. O. Box 1, Kyambogo, Kampala, Uganda. \\ ${ }^{2}$ Business Administration and Entrepreneurship, Kyambogo University, P. O. Box 1, Kyambogo, Kampala, Uganda. \\ ${ }^{3}$ Department of Quality Assurance, Kyambogo University, P. O. Box 1, Kyambogo, Kampala, Uganda. \\ * ORCID: http://orcid.org/0000-0003-2337-0541; Author for Correspondence Email: maryoyonyeko@gmail.com.
}

Article DOI: https://doi.org/10.37284/eajes.2.1.243

\section{Date Published: ABSTRACT}

30 November 2020 The purpose of this study was to establish the relationship between goal setting and quality of lecturers' services. This was based on the deteriorating quality Keywords: of lecturers' services in Makerere University, the pioneer university in Uganda.

Goal-Setting,

Teaching,

Research Supervision,

Publication,

Community Services.

The study was a cross-sectional survey, targeting academic staff in College of

Humanity and Social Sciences (CHUSS), College of Commerce and Business

Administration (CoBAMS) and College of Education and External Studies (CEES). These lecturers were selected using simple random sampling technique. Data was collected using a self-administered questionnaire. It was analysed using Pearson's correlation coefficient index and regression analysis techniques. Results revealed that there was a highly positive significant impact between goal setting and quality of lecturers' services (teaching, research supervision, writing and publication, and finally community services). It was hence concluded that goal setting is a strong predictor of quality of lecturers' services. Thus, a recommendation that once lecturers' quality of services is to be enhanced at Makerere University there should be high engagement of lecturers on boards, council, senate to influence decisions geared towards achieving university objectives missions and goals.

\section{APA CITATION}

Anyango, M., Kamaduuka, R., \& Kaahwa, G. (2020). Influence of Instructional Resources Provision and Performance in Mathematics Subject in Public Girls Secondary Schools Baringo Central Sub-County. East African Journal of Education Studies, 2(1), 161-172. https://doi.org/10.37284/eajes.2.1.243.

\section{CHICAGO CITATION}

Anyango, Mary, Regis Kamaduuka, and Goretti Kaahwa. 2020. "Performance Management and Quality of Lecturers' Services at Makerere University". East African Journal of Education Studies 2 (1), 161-172. https://doi.org/10.37284/eajes.2.1.243. 


\section{HARVARD CITATION}

Anyango, M., Kamaduuka, R. and Kaahwa, G. (2020) "Performance Management and Quality of Lecturers' Services at Makerere University", East African Journal of Education Studies, 2(1), pp. 161-172. doi: 10.37284/eajes.2.1.243.

\section{IEEE CITATION}

M. Anyango, R. Kamaduuka, and G. Kaahwa, "Performance Management and Quality of Lecturers' Services at Makerere University”, EAJES, vol. 2, no. 1, pp. 161-172, Nov. 2020.

\section{MLA CITATION}

Anyango, Mary, Regis Kamaduuka, and Goretti Kaahwa. "Performance Management and Quality of Lecturers' Services at Makerere University". East African Journal of Education Studies, Vol. 2, no. 1, Nov. 2020, pp. 161-172, doi:10.37284/eajes.2.1.243.

\section{INTRODUCTION}

Performance management plays an important role in improving the quality of services offered in universities by the lecturers. As explained in various external assessment of teaching, it has attracted concerns among scholars in the United Kingdom's high education since the 1980s. More adoption of modern technologies and innovations in the UK's higher education have been utilized with the aim of improving quality services among the people in higher education (Great-batch and Holland, 2016). But performance management has been given little attention in improving the quality of services among employees in the education sector.

Studies on regular in-service programmes, workshops, seminars, conferences for both academic and non-academic staff have been found to improve on the quality of services among employees in universities (Ebisine, 2015). Phillips (2008) conducted a study on professional development and quality of teachers' services and found out that equipping teachers with adequate knowledge improves their quality of services.

Asamoah \& Mackin (2015) revealed that inadequate lecturers research activities, irrelevant programmes, curriculum and instructional methodologies were the key breaking fetters in university higher education provision in SubSaharan Africa. Obwongi (2011) studied factors that affect the quality of teaching among academic staff in Higher Education in Kenya and with the use of regression analysis established that human resource practices in universities significantly affect the quality of teaching. The two studies did not address the three dimensions of quality of lecturers' services as this proposed study will do in Makerere University.

Mutiso (2013) studied the relationship between human resource management practices and teachers' quality service delivery in Kenyan public secondary and tertiary institutes in Taita Taveta County. The study indicated that there is a positive significant relationship between human resource management and teacher's quality service delivery. Netshifhefhe et al. (2016) studied quality assuring teaching and learning processes in higher education and with the review of literature established that quality assurance in teaching and learning activities especially in determining what courses programmes, the content was still a major challenge on the side of teaching staff. In Uganda, Kasule and Bisaso (2016) studied university administrative staff competence and quality of service delivery in public universities in Uganda and revealed that there is a significant relationship between administrative staff competence and quality of service being provided at Kyambogo University. From the above-reviewed studies, not all performance management dimensions have been studied in relation to the quality of lecturers' services in universities.

In Makerere University, Ezati, Opolot-Okurut \& Ssentamu (2014) showed that although effective teaching and learning is at the heart of teaching and learning quality assurance policy of Makerere University, teaching has relatively remained poor. However, teaching is one out of the three services academic staff are expected to offer. This calls for an urgency for this study to be carried to establish the extent to which the quality of lecturers' services in Makerere University. 


\section{Problem Statement}

Quality of lecturers' services is essential in the realization of university vision, mission and objectives through proper effective performance management. Quality of lecturers' services depends on several issues such as administrative staff inputs (Kasule and Bisaso, 2016), professional development (Phillips, 2008) with the aim of improving lecturers' quality of services. In line with the above statement, universities have put in place a quality assurance unit to ensure that the quality of services remains high (Philips, 2008). However, Rwendeire's (2017) report also (Makerere University Annual Report 2017); Azikuru, Onen and Ezati (2017); and Makerere University Quality Assurance (2013) reported that there are some weaknesses in the quality of lecturers' services offered at Makerere University. For instance, there is poor teaching methods applied, inadequate teaching preparation and untimely content coverage as well as poor assessment. While in the area of research processes, there is low students' supervision and attending viva voce. Low quality of lectures' services was exposed by lecturers not getting involved in solving community issues, engaging in political affairs and community dialogue, indicated in the report as not effectively (Musinguzi, Ssonko, Waiswa, Kabanda and Wareba, 2016). Makerere University reports (2018) stated that the quality of teaching by academic staff is going down in the University with too much attention put on research and publication. Supervision of students in research is poorly done, leaving some students complaining and dropping out of the University. Kasozi (2019) and Matovu (2017) pointed out that there is no system put in place to enhance quality service of academic staff and therefore ending up pitiable services to stakeholders. Community services were rarely done. This low quality of service delivery by lecturers is likely to affect their reputation in the university, community and the public. This study was set to establish the influence of goal setting on the quality of lecturers' services in Makerere University with the aim of improving the services offered by the lecturers in the university.

The primary aim of the study was to establish the relationship between goal setting, staff and quality of lecturers' services in relation to teaching, research supervision, research writing and publication and community service Makerere University. The research objective was to establish the relationship between goals setting of the university and the quality of lecturers' services in Makerere University. It was hypothesised that there was statistically a positive relationship between goal setting and quality of lecturers' services at Makerere University.

\section{Significance of the Study}

The study findings would be significant to Makerere University Cas they will be informed of how performance management studied relates with quality of lecturer's services to formulate so that it may be used to strengthen the existing policies that would, in turn, improve on the quality of lecturers' services at the university.

To the lecturers in the university, the study findings would help them to align their task objectives to that of the university goals and redesign policies that strengthen the existing ones to improve on the quality of their services based on the nature of relationships established. The study findings would be essential to the students since when home resources studied are improved, lecturers would effectively deliver quality services leading to the provision of quality university education.

The study findings would essential to future researchers when they would use them as a source of reference in their suggested studies while identifying more gaps. The policymakers will also use the findings to design appropriate training skills for each group of lecturers in the university. Education officers would use the research finding report to improve on their service of work in term of coordination and support in budget allocation for the staff they supervised. The research findings if adopted by the administrative structures would improve on the service deliveries by lecturers in Makerere and other public universities in Uganda and in the diaspora.

\section{Theoretical Perspective}

Goal Setting Theory (Locke, 1990) puts forward the 'Goal-setting theory of motivation'. This theory states that goal setting is essentially linked to task performance. It states that specific and challenging 
goals along with appropriate feedback contribute to higher and better task performance. The theory relates to the study in the way that once academic staff are involved in setting goals, mission, planning and in setting objectives in the various strategic plans of the university, there is a high possibility that the quality of lecturers' services in terms of teaching writing and publication, supervision and engagement in community services improves and the reverse is true.

\section{Conceptual Perspective}

Quality of lecturers' services, defined by Szymenderski, Yagudina and Burenkova (2015) as a working operation on which lecturer's services are compliant with the pre-established standards. Phillips (2008) defines quality of lecturers' services as the extent to which lecturers work meets students and stakeholders' expectations to increase on the lecturers' quality of services by meeting deadlines and improving on their services in the universities. Quality of service according to Kasule and Bisaso (2016) is defined as the extent to which the service meets the expectations of clients. Quality of lecturers' services is assessed basing on teaching, research work, and community services. Performance management refers to activities designed to provide an employee with necessary skills, knowledge and attitudes by the organization so that their quality of services is improved (Mutiso, 2013). Sauers and Bass (1990) define goal-setting aspect of performance management as a formal program of setting numerical or quantitative performance goals for individuals and that all formal goal-setting programs share the common objectives of increasing quality of employees of services. Mills (2002) define goal setting as representing "a way of keeping score" and that "by helping employees define their personal goals, managers are putting them on the path towards achieving the organization's goals to improve quality of services.

Goal setting means aligning lecturers' work objectives to the mission and aim of the institution (Makerere University). The diagram below shows the influence of performance management on quality of lecturers' services at Makerere University.

Figure 1: Influence of performance management on quality of lecturers' services in Makerere University.

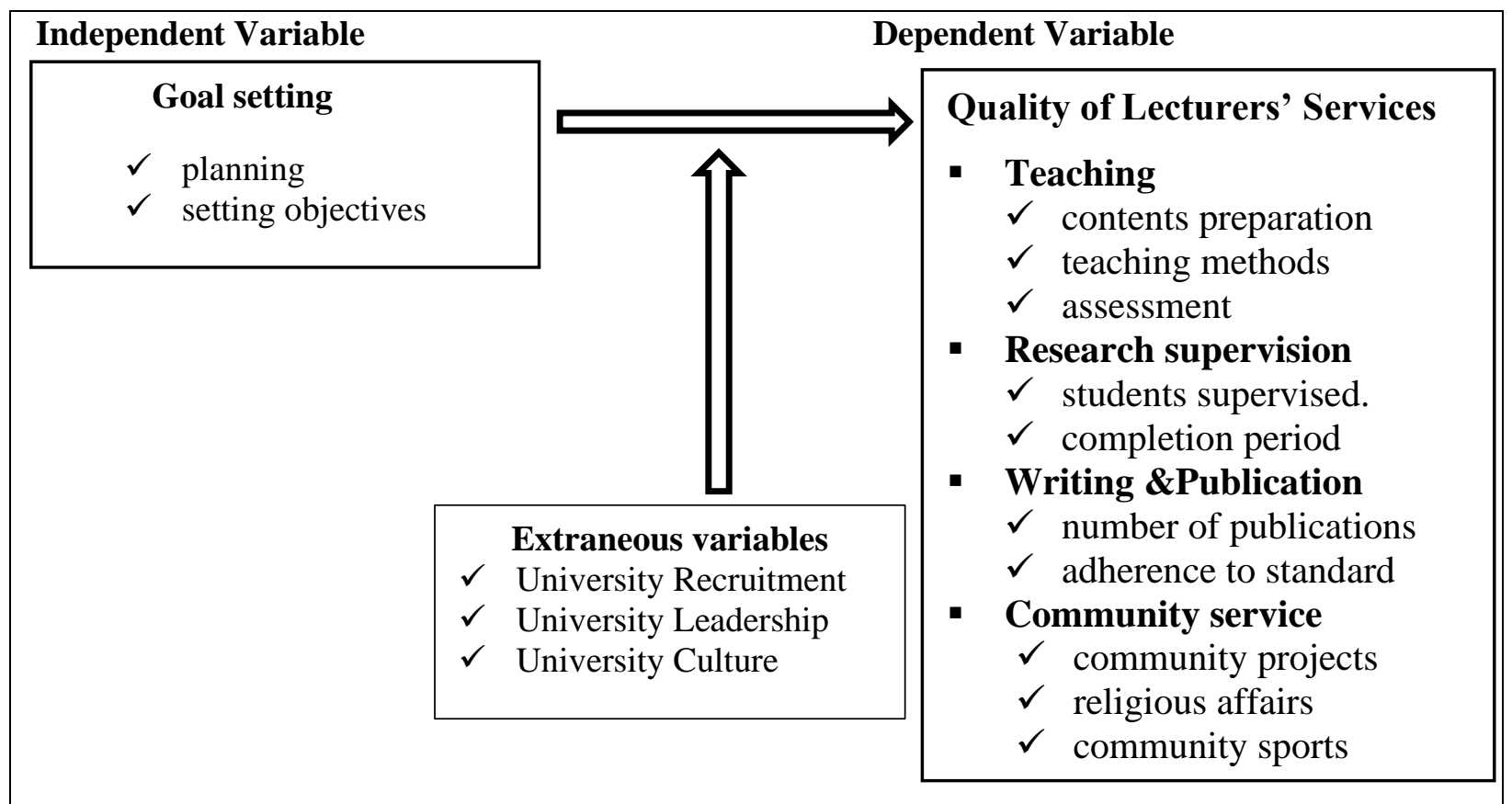

Source: (Mutiso, 2013) 
The conceptual framework in Figure 1 above shows the independent variable which was performance management (goal setting, would influence the dependent variables (teaching, research supervision, community services and research writing and publication). The extraneous variables consist of the university policies, university leadership and university cultures. They do not have literatures reviewed up on but each of he has influences on the quality of lecturers' services in the university.

\section{Goal Setting and Quality of Lecturers' Services}

Ordonez et al. (2009) revealed that goal setting has a substantial impact on research, teaching and general education services. Setting challenging goals boosts employee's performance and quality of their work outcomes. This was a review of literature, not a field study finding as the suggested study was in Makerere University. Esposito and Virile (2015) studied improving student success with goal setting theory and established that goalsetting theory enables teachers to effectively teach learners, assess, and participate in giving students feedback from the learning process. The goalsetting approach highly improves on teachers teaching and students' learning. The study was a review of literature and was not carried out in a developing world context, but the proposed study was in Uganda.

Slightly differing from the earlier studies, Lavack et al. (2015) studied goal setting and strategies to enhance goal pursuit for adults and with use of descriptive analysis established that there were inconclusive results regarding whether structured goal-setting approaches result into quality of worklife, participation into work-related activities and employees' attitudes towards work. Besides, this was a descriptive study and did not capture the relationship between goal setting and quality of academic staff services in an academic context.

Mitchell and Daniels (2003) as cited by Latham and Pinder (2005) argue that goal setting "is quite easily the single most dominant theory in the field with over a thousand articles. Locke and Latham (1990) reinforced the argument that there is strong reason to conclude that goal-setting works at the group and organizational (or unit) level as well as at the individual level. Some organizations like XYZ, have also come to realize that to be relevant in the current and competitive and globalized business environment, there is a need to constantly re-assess the competitive imperatives to remain viable with the organizational goals. This study was based on descriptive results like frequencies and percentages while the proposed study was, in addition, correlational.

\section{METHODOLOGY}

The study was a cross-sectional and correlational survey designs. The study respondents were 58 lecturers from Makerere University colleges CEES, CoBAMS and CHUSS. Respondents from these colleges were selected using simple random sampling technique. Data was collected using a self-administered questionnaire and analyzed using Pearson's correlation coefficient index and regression analysis methods.

\section{RESULTS}

In this section, the presentation of results obtained in the study is offered. These results are offered beginning with respondents' biodata and results from goal setting, and on quality of lecturers' services and finally on testing of the study hypothesis.

Table 1: Respondents' Demographics

\begin{tabular}{llll}
\hline Variable & Category & Frequency & Percent \\
\hline Gender & Male & 35 & 60.3 \\
& Female & 23 & 39.7 \\
\hline Age & $30-35$ yrs & 6 & 10.3 \\
& $36-40$ yrs & 22 & 37.9 \\
& $41-45$ yrs & 16 & 27.6 \\
& $46-50$ yrs & 4 & 6.9 \\
& 51 plus & 4 & 6.9 \\
\hline Qualification & First & 6 & 10.3 \\
& degree & & \\
& Master's & 31 & 53.4 \\
& degree & & \\
\hline Marital status & PhD & 21 & 36.1 \\
\hline Single & 18 & 31.4 \\
& Married & 38 & 65.0 \\
\hline & CEES & 21 & 36.2 \\
& CHUSS & 10 & 17.2 \\
& CoBAMS & 27 & 46.6 \\
\hline
\end{tabular}




\begin{tabular}{llll}
\hline Variable & Category & Frequency & Percent \\
\hline Rank & Part-time & 05 & 8.6 \\
& $\begin{array}{l}\text { Teaching } \\
\text { assistant }\end{array}$ & 18 & 31.0 \\
& $\begin{array}{l}\text { Junior } \\
\text { lecturer }\end{array}$ & 2 & 3.4 \\
& $\begin{array}{l}\text { Lecturer } \\
\text { Senior }\end{array}$ & 10 & 17.2 \\
& $\begin{array}{l}\text { lecturer } \\
\text { Associate }\end{array}$ & 02 & 27.6 \\
professor & & 3.4 \\
& Professor & 05 & 8.6 \\
\hline
\end{tabular}

Table 1 shows that most of the study respondents were male $60.3 \%$ as opposed to $39.7 \%$ who were females. This may predict that there are more male lecturers than females at Makerere University. Results also indicate that most of the study respondents were of ages between 36-40 years $(37.9 \%)$, few were of age 51 plus years $(6.9 \%)$. These results showed that most academic staff at Makerere University are below retirement age, hence in their productive age.

Regarding qualifications, most of the academic staff were master's degree holders $31(53.4 \%)$ followed by 21 (36.2\%) $\mathrm{PhD}$ holders and $6(10.3 \%)$ were first degree holders. This finding reflected that since most of them were master's degree holders, their productivity/ quality of service may be negatively affected. Table 1 shows that a big majority of academic staff $38(65.5 \%)$ were married compared to $18(31 \%)$ who were single. This reflects that they are mature enough to pay a high degree of commitment to the job.

Results indicated also that many of the respondents were from CoBAMS, 27 (44.3\%), followed by 21 (36.2\%) from CEES while $10(17.2 \%)$ were from CHUSS. These results indicated that CoBAMS was highly represented in the study.
On academic staff rank, many of the respondents 18 (29.5\%) were teaching assistants, followed by 16 (26.2\%) senior lecturers, followed by $10(17.2 \%)$ lecturers while the least representation were senior lecturers and associate professors each represented by $2(3.3 \%)$. The rank of staff shows that junior ranks are more represented while senior ranks are less represented which depicts a true picture of the current academic staff establishment. Finally, on experience, many of the academic staff $31(53.4 \%)$ were of experience 11-20 years, while 0-10 years and 21-30 years had equal representation $20.7 \%$. This experience indicated that academic staff had spent some reasonable time at work which may be a sign of quality services.

\section{Descriptive Result on Goal Setting and Quality of Lecturers' Services}

Table 2 results shows that the highest mean 3.844 on the item the staff work objectives are measurable almost equal to code $4=$ agree. This meant that staff work objectives are measurable.

This was followed by goal setting with mean 3.620 on item 'the staff objectives are aligned to that of the university'. This mean was almost close to code $4=$ agree on the scale used. It suggested that they had agreed that their objectives follow those of the university.

Table 2 shows that the least rating was on item 'there is a strategic plan for staff work' with a mean of 2.948, which was almost equal to code 3 not sure. The mean values, in general, were almost inclined to code 4 suggesting agreement with goals setting among academic staff in the execution of their services. The standard deviations are all low implying that they had similar views and opinions on items of goal setting.

Table 2: Means, standard deviations on goal setting

\begin{tabular}{lll}
\hline Item & Means & Std. Dev \\
\hline There is a strategic plan for staff work & 2.948 & 0.8465 \\
There is a clear mission for staff work in the strategic plan & 3.362 & 0.852 \\
There is a clear vision for staff work & 3.534 & 0.772 \\
My university has objectives for staff work & 3.448 & 0.901 \\
The work objectives are measurable & 3.569 & 0.651 \\
The staff work objectives are measurable & 3.844 & 0.643
\end{tabular}


East African Journal of Education Studies, Volume 2, Issue 1, 2020

Article DOI: https://doi.org/10.37284/eajes.2.1.243

\begin{tabular}{lll}
\hline Item & Means & Std. Dev \\
\hline The objectives are aligned to that of the university & 3.620 & 0.670 \\
My university has a clear road map followed by staff & 3.482 & 0.922 \\
My university strategic plan is periodically reviewed & 3.569 & 0.678 \\
\hline
\end{tabular}

\section{Lecturers' Quality of Services}

Lecturers quality of services was considered basing on lecturers teaching, research supervision, research writing and publication and finally community services.

\section{Teaching}

Lecturers teaching was studied using 10 qualitative items and results are provided in Table 3. Results on teaching quality show that the highest mean value was mean 3.844 almost equal to code $4=$ agree and standard deviation 0.744 which was also low implying that respondents' views did not vary so much from one respondent to another. This mean was followed by mean 3.689 also almost equal to 4 $=$ agree and standard deviation 0.7992 lowest rating on quality of teaching services was mean 3.517 almost equal to code $4=$ agree and standard deviation 0.7312 which was also very low. These means suggested that study respondents had agreed that the quality of their teaching was high. The standard deviations on all items were low suggesting that respondents' views did not vary so much from one respondent to another.

Table 3: Means and standards deviations on teaching quality

\begin{tabular}{lll}
\hline Item & Means & Std. Div \\
\hline I engage in providing students with learning materials & 3.5517 & 0.882 \\
I do timely student assessment & 3.5172 & 0.7312 \\
I use varied lecturing methods & 3.844 & 0.744 \\
I complete the syllabi on time & 3.655 & 0.7620 \\
I select and use appropriate pedagogies that suits each student & 3.655 & 0.608 \\
I fairly assess students work & 3.603 & 0.972 \\
I timely analyse learner results and submit to the college & 3.655 & 0.663 \\
I give timely feedback to students & 3.689 & 0.7992 \\
I organize seminars and workshops to students & 3.655 & 0.547 \\
I prepare adequate teaching aid and materials to students & 3.637 & 0.872 \\
\hline
\end{tabular}

\section{Research Supervision}

Lecturers quality of research services were also operationalized using 10 quantitative items on which study respondents were required to do selfrating using a scale ranging from $1=$ strongly disagree, $2=$ disagree, $3=$ not sure, $4=$ agree and $5=$ strongly agree. Results are offered in Table 4.

Table 4: Descriptive results of lecturers' research quality

\begin{tabular}{lll}
\hline Items on research quality & Means & Std. Div \\
\hline I have a standard number of student supervisees of 2-3 PhD & 3.672 & 0.710 \\
I diligently supervise master's students assigned to me & 3.603 & 0.560 \\
I ensure that students topics meet required standards & 3.827 & 0.625 \\
I participate in student's viva assessment and voce & 3.756 & 0.601 \\
I timely supervise student research works & 3.827 & 0.596 \\
I encourage students to attend viva & 3.586 & 0.7263 \\
I mark student viva corrections before final submission & 3.586 & 0.773 \\
I encourage students follow systematic research application & 3.482 & 0.863 \\
All students I supervise publish their research work & 3.862 & 0.633
\end{tabular}




\begin{tabular}{lll}
\hline Items on research quality & Means & Std. Div \\
$\begin{array}{l}\text { I encourage the students I supervise to identify an international journal for } 3.586 \\
\text { publication }\end{array}$ & 0.726 \\
\hline
\end{tabular}

Table 4 shows that respondents rated highly on item 'all students I supervise publish their research work' mean 3.862 with a low standard deviation 0.633 , followed by mean 3.827 on item 'I timely supervise student research work'. The mean values to a great extent are almost equal to code $4=$ agree. This meant that the quality of lecturers' research supervision is too high. The standard deviations revealed that all standard deviation was low as the highest standard deviation was 0.773 and the lowest standard deviation was 0.560 on items 'I diligently supervise masters students assigned to me'. This showed that respondents did not vary so much from one respondent to another.

\section{Research Writing and Publication}

Research writing and publication was also studied using 10 items on which respondents were requested to self-rating and results are provided in Table 5.

Table 5: Means and standard deviations on research writing and publication

\begin{tabular}{lll}
\hline Item & Means & Std. Div \\
\hline I write 4 journal publications in one academic year & 3.793 & 0.614 \\
I do publish in edited books & 3.827 & 0.596 \\
I do publish in known journals & 3.885 & 0.634 \\
I always give innovative ideas on how best publications are made to students & 3.724 & 0.720 \\
I encourage students to publish their research reports & 3.896 & 0.640 \\
I encourage students to follow and use the correct criteria on research publication in 3.775 & 0.838 \\
journals & & \\
I encourage students to read other people's publications & 3.810 & 0.661 \\
My students participate in journal writing competitions & 3.689 & 0.7992 \\
I organize benchmarking conference tours for my students & 3.948 & 0.574 \\
I give out students' theses to other lecturers to read and give students & 3.827 & 0.534 \\
\hline
\end{tabular}

Results in Table 5 indicate that the highest mean was 3.948 on item 'I organize benchmarking conference tours for my students'. This mean value was almost equal to code $4=$ agree. This implied agreement with organizing student conference tours. This mean was followed by mean 3.896 on item 'I encourage my students to publish their research reports'. The means imply that academic staff had agreed that their quality of research writing and publication was high. The highest standard deviation 0.838 was on item 'I encourage students to follow and use the correct criteria on research publication in journals' and the lowest standard deviation was 0.574 on item 'I organize benchmarking conference tours for my students'. These standard deviations were all low implying that respondents did not differ so much from one respondent to another.

\section{Community Services}

Community services in this study were studied using 10 items. Lecturers were thus requested to do self-rating on these items using a scale where $1=$ strongly disagree, $2=$ disagree, $3=$ not sure, $4=$ agree and $5=$ strongly agree. Results on this are offered in Table 6. 
Table 6: Descriptive results on community services

\begin{tabular}{lrl}
\hline Items on community services & Means & Std. Div \\
\hline I participate in formulating community ordinances & 3.706 & 0.530 \\
I participate in community projects & 3.672 & 0.659 \\
I engage in the selection of Makerere University Council & 3.844 & 0.586 \\
I participate in planning community needs & 3.758 & 0.732 \\
I support some community activities i.e. sports, skills improvement & 3.672 & 0.758 \\
I support some community problems and develop research projects to solve the 3.586 & 0.773 \\
problems & & \\
I submit periodical reports to the head of department & 3.741 & 0.663 \\
I provide students results in time & 3.517 & 0.842 \\
I participate in local council elections in my community & 3.793 & 0.642 \\
\hline
\end{tabular}

Table 6 results indicate that the highest mean 3.844 implying that academic staff had agreed that they engage in the selection of Makerere University Council followed by mean 3.793 was almost equal to code $4=$ agree. This meant that academic staff highly participate in local council elections in their communities. The mean values were almost equal to code $4=$ agree. The standard deviations showed that the highest standard deviation was 0.758 on item 'I support some community activities i.e. sports skills improvement' and lowest standard deviation 0.530 on item 'I participate in formulating community ordinances'. These standard deviations were all low suggesting that they had similar views and opinions regarding engagement in community services.

\section{Testing of the Study Hypotheses}

Testing of the study hypothesis $\mathrm{H}_{1}=$ Goal setting has a positive relationship quality of lecturers' services. To test this hypothesis quality of lecturers' services that is, teaching services, research supervision, research writing and publication together with community services were aggregated into one index quality of lecturers' services. Thus, this hypothesis was first tested using Pearson's correlation coefficient index and later simple linear regression analysis as in Table 7.

Table 7: Pearson's correlation coefficient index showing the relationship between goal setting and quality of lecturers' services

\begin{tabular}{llll}
\hline & & Goal setting & Lecturers quality of services \\
\hline Goal setting & Pearson correlation & 1 & $0.522^{* *}$ \\
& Sig 2-tailed & & 0.000 \\
& $\mathrm{~N}$ & 58 & 54 \\
Quality of lecturers' services & Pearson correlation & $0.522^{* *}$ & 1 \\
& Sig 2-tailed & 0.000 & \\
& $\mathrm{~N}$ & 54 & 54 \\
\hline
\end{tabular}

**Correlation is significant at 0.01

Table 7 shows Pearson's correlation coefficient index between goal setting and quality of lecturers' services $r=0.522^{* *}, \mathrm{Sig}=0.000$ less than 0.05 . This implied that there was a highly positive significant relationship between goal setting and quality of lecturers' services at the one percent level. These findings implied that through setting clear goals in Makerere University with lecturers' involvement and consultation, quality of their services would improve and the reverse is true.

The regression analysis results in Table 8, 9 and 10 also confirm Pearson's correlation coefficient results. 
East African Journal of Education Studies, Volume 2, Issue 1, 2020

Article DOI: https://doi.org/10.37284/eajes.2.1.243

Table 8: Model summary table on goal setting and quality of lecturers' services.

\begin{tabular}{lllll}
\hline Model & R & R Square & Adjusted R Square & Std. Error of the Estimate \\
\hline 1 & $.522^{\text {a }}$ & .273 & .259 & .34976 \\
\hline a. Predictors: (Constant), Goals & &
\end{tabular}

The model summary table shows adjusted $r^{2}=$ 0.259 which meant that goal-setting explained only $25 \%$ of the change in the quality of lecturers' service

Table 9: Correlation of goal setting and lecturers' quality of services

\begin{tabular}{|c|c|c|c|c|c|c|}
\hline \multicolumn{7}{|c|}{ Coefficients $^{\mathbf{a}}$} \\
\hline \multirow[t]{3}{*}{ Model } & & Unstandardized & & Standardized & $\mathrm{t}$ & Sig. \\
\hline & & Coefficients & & Coefficients & & \\
\hline & & $\mathrm{B}$ & Std. Error & Beta & & \\
\hline \multirow[t]{2}{*}{1} & (Constant) & 2.461 & 0.306 & & 8.035 & 0 \\
\hline & Goals & 0.383 & 0.087 & 0.522 & 4.416 & 0 \\
\hline
\end{tabular}

a. Dependent Variable: Quality of lecturer' services.

The coefficient table below shows the Beta value 0.522 and significance value 0.000 . Since the significance P-value is less than 0.05 , it finally suggested a highly positive significant relationship between goal setting and lecturers' quality of services.

Table 10: ANOVA table on goal setting and lecturers' quality of services

\begin{tabular}{lllllll}
\hline ANOVA $^{\mathbf{a}}$ & & & & & & \\
\hline Model & & Sum of Squares & df & Mean Square & F & Sig. \\
1 & Regression & 2.385 & 1 & 2.385 & 19.498 & $.000 \mathrm{~b}$ \\
& Residual & 6.361 & 52 & 0.122 & & \\
& Total & $\mathbf{8 . 7 4 7}$ & $\mathbf{5 3}$ & & & \\
\hline
\end{tabular}

a. Dependent Variable: Quality of lecturers'services.

b. Predictors: (Constant), Goals

The ANOVA table shows the F-value 19-498 and significance value 0.00 which implied that there was a significant positive relationship between goal setting and quality lecturers' of services.

\section{CONCLUSIONS AND RECOMMENDATIONS}

The findings of the study revealed a highly positive significant relationship between goal setting and quality of lecturers' services at Makerere University. These findings implied that as academic staff are engaged in goal setting that is, on setting goals, objectives, setting strategic plans and following them up. The higher these academic staff would have their services improve in teaching, carrying out supervision, research and publication and engaging highly in community outreach services. These findings are directly supported by Ordonez., Schweitzer, Galinsky, \& Bazerman, (2009) who revealed that goal setting has a substantial impact on research, teaching and general education services. Setting challenging goals boosts employee's performance and quality of their work outcomes. This finding was in direct agreement with Esposito and Virili (2015) studied improving student success with goal setting theory and established that goal-setting theory enables teachers to effectively teach learners, assess, and participate in giving students feedback from the learning process. In conclusion goal setting has a highly positive significant relationship on quality of lecturers' services at Makerere University, hence it is recommended that to have quality of lecturers' services improved at Makerere University, there should be high involvement of academic staff in 
training the mission, objectives, goals of the university in the various strategic plans made. This might also be through ensuring that academic staff are fairly represented on decision-making committees, university council, senate, academic boards in each college.

\section{REFERENCE}

Asamoah, M. K. \& Meckin, E. E. (2015). Breaking fetters of higher education in sub-Saharan Africa. International Journal of Educational Administration and Policy Studies. 7(1), 6-16, Doi: 10.5897/IJEAPS2015.0387

Azikuru, L. M. E., Onen, D. \& Ezati, B. A. (2017). Staffing and the quality of teaching in universities. European Journal of Educational Studies, 3(3), 21-36, doi:10.5281/zenado.268381.

Ebisine S. S. (2015). Human resource development: imperatives for achieving quality assurance in higher education in Nigeria. Journal of Educational and Social Research.

Esposito, M. and Virili, F. (2015). Improving student success with goal setting theory. A literature review. Dipartimento, di scienze economiche. e.azie ndali, universita-degli studi di sassar

Ezati, B. A., Opolot-Okurut, C. \& Ssentamu, P. N. (2014). Addressing pedagogical training needs of teaching staff. Lessons from Makerere University short professional programs 20062010. American Journal of Educational Research, 2(12), 1190-1198. Doi: 10.12691/education-2-12-19

Great-batch, D. \& Holland, J. (2016). Teaching quality in higher education. Literature review and qualitative research. Department of Business, Innovation and Skills. Hust policy research.

Kasule, G. W., \& Bisaso, R. (2016). University administrative staff competence and quality of service delivery in a Ugandan public university. International Journal of Education and Research, 4(11), 165-174.
Latham, G. P. \& Pinder, C. C. (2005), "Work motivation theory and research at the dawn of the twenty-first century", Annual Review of Psychology, Vol. 56, pp. 485-516.

Lavack, M. M. M., Weatherall, M., Hay-Smith, E. S. C., Dean, S. G. \& Siergert, R. J. (2015). Goal setting and strategies to enhance goal pursuit for adults acquired disability participating in rehabilitation. Review, Cochrane Database Systematic Review, 7(1), 1-201. Doi: 10.1002/14. 651858.CD09727.

Locke, E. A. \& Latham, G. P. (1990), A theory of goal setting \& task performance, Prentice Hall, Inc, USA.

Makerere University (2017) Quality assurance policy department.

Mills, C. (2002). Performance management under the microscope, Singapore Human Resources Institute, Singapore. Rob

Musinguzi, B., Ssonko, M., Waiswa, J., Kabanda, M. \& Wareba, S. (2016). The integration of community outreach into teaching and learning, research and community service in Makerere, Uganda Christian and Uganda Martyrs Universities. Uganda Christian University.

Mutiso, M. C. (2013). Relationship between human resource management practices and quality service delivery in Kenyan public secondary schools in Taita Taveta County. Master Thesis. Kenyatta University.

Obwongi, J. (2011). Factors that affect the quality of teaching in universities in Kenya. Doctor of philosophy in human resource studies. Nairobi University, Kenya

Ordonez, L. D., Schweitzer, M. E., Galinsky, A. D., \& Bazerman, M. H. (2009). Goals gone wild. The systematic side effects of over-prescribing goal setting. Harvard Business School, working paper.

Philips, P. (2008). Professional development as a critical component for continuing teacher quality.Australian Journal of Teacher Education, 33(1), 37-44. 
Rwendeire A. (2017) Makerere University Annual Report.

Sauers, D. A. \& Bass, K. (1990). Sustaining the positive effects of goal setting: The positive influence of peer competition. Akron Business and Economic Review, 21 (4), 30-30.

Szymenderski, P., Yagudina, L. \& Burenkova, O. (2015). The impact of an assurance system on the quality of teaching and learning: Using the example of university in Russia and one of the universities in Germany. Higher Education Studies, 5(5), 15-25. 